\section{§7. Microstructure of Creep-deformed V-4Cr-4Ti Strengthened by Precipitation and Cold Rolling}

Muroga, T., Nagasaka, T.,

Chen, J.M. (SWIP), Li, Y.F. (Grad. Univ. Advanced Studies)

One of the factors limiting the upper operation temperature of vanadium alloys is thermal creep performance. Among the means to enhance the high temperature strength of the reference $\mathrm{V}-4 \mathrm{Cr}-4 \mathrm{Ti}$ alloys is to induce high density of precipitates in the matrix.

The objective of the present study is to obtain insight into the mechanism of the effect of thermal and mechanical treatment on the creep performance, with respect to the evolution of dislocations and precipitates.

The material used in this study was the reference $\mathrm{V}-4 \mathrm{Cr}-4 \mathrm{Ti}$ alloy named NIFS-Heat-2. The as-received alloy plates were $0.5-1 \mathrm{~mm}$ thick and in the cold rolled state of $>90 \%$ reduction in thickness. Four thermal and mechanical treatments were applied to these plates, which are summarized in Table 1 . The creep test specimens had the gauge dimension of $5 \times 1.2 \times 0.25 \mathrm{~mm}^{3}$ (SS-J size).

Creep test was conducted for STD and SAACW specimens at $1023 \mathrm{~K}$ with the applied tensile stress of 176 $\mathrm{MPa}$ and $250 \mathrm{MPa}$ in vacuum of $<4 \times 10^{-5} \mathrm{~Pa}$ using a uniaxial creep test machine for miniaturized tensile test specimens. Uniaxial and constant load was applied to the specimen by load blocks. For microstructure analysis by transmission electron microscope (TEM), $3 \mathrm{~mm}$ disks were punched-out from the gauge area of the specimens after the creep test. For comparison, thermal aging of SAA, STDCW, SAACW specimens was carried out in heat histories identical to those of the creep tests.

Creep tests showed that SAACW specimens showed lower creep strain rate than STD specimens. The tests were terminated for TEM observation. Fig. 1 compares microstructure of SAACW after creep deformation for $80 \mathrm{~h}$ with $176 \mathrm{MPa}$ at $1023 \mathrm{~K}$ and after the identical heat treatment $(80 \mathrm{~h}$ at $1023 \mathrm{~K})$ without any applied stress. In the case of after creep deformation, the direction of the applied tensile force was shown in the photograph. The photographs clearly show the difference in the dislocation morphology. After creep deformation, most dislocations are oriented to particular directions, while with only thermal aging, directions of the dislocations are more complex. Identification of the Burgers vector of the dislocation was carried out using a $\boldsymbol{g} \times \boldsymbol{b}=0$ technique.

Table 1 The thermal and mechanical treatment conditions

\begin{tabular}{|c|c|c|}
\hline Abbreviation & Treatment & Conditions \\
\hline STD & Standard & $1273 \mathrm{~K}, 2 \mathrm{~h}$ \\
\hline \multirow{2}{*}{ STDCW } & Standard and Cold-rolled & $\begin{array}{c}\text { STD }+20 \% \\
\text { Cold Rolled }\end{array}$ \\
\hline \multirow{2}{*}{ SAA } & Solution Annealed and & $\begin{array}{c}1373 \mathrm{~K}, 1 \mathrm{~h}+ \\
873 \mathrm{~K}, 20 \mathrm{~h}\end{array}$ \\
\hline \multirow{2}{*}{ SAACW } & Aged & $\begin{array}{c}\text { Solution Annealed, Aged } \\
\text { and Cold-rolled }\end{array}$ \\
& \multicolumn{2}{|c}{ Cold Rolled } \\
\hline
\end{tabular}

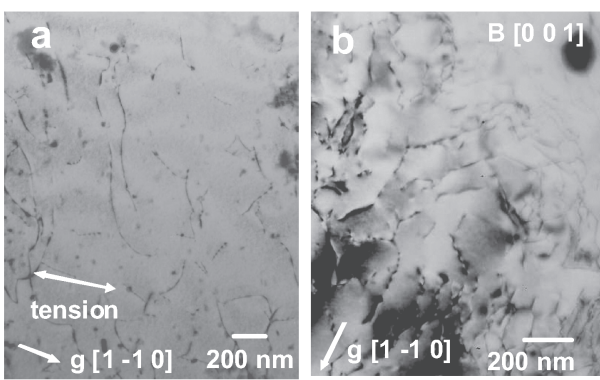

Fig. 1 Dislocation structure of SAACW specimens after (a) creep deformation with $176 \mathrm{MPa}$ at $1023 \mathrm{~K}$ for $80 \mathrm{~h}$, and (b) thermal aging in an identical thermal condition (1023 K, $80 \mathrm{~h})$.

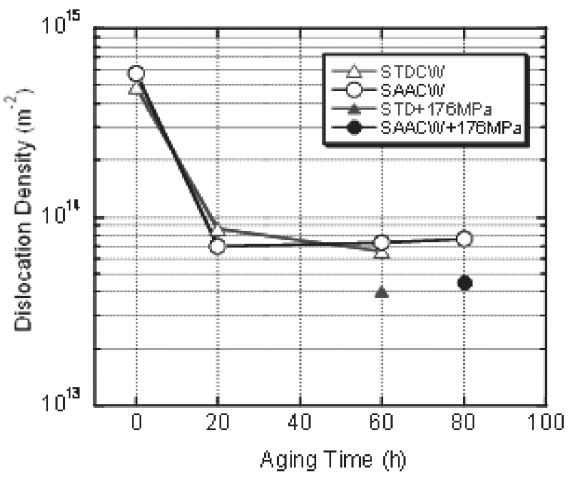

Fig. 2 Dislocation density as a function of the aging time at $1023 \mathrm{~K}$ for STDCW and SAACW.

Dislocation densities of STD and SAACW specimens after creep tests with $176 \mathrm{MPa}$ at $1023 \mathrm{~K}$ for $60 \mathrm{~h}$ and $80 \mathrm{~h}$, respectively, are also indicated.

The result showed that the dislocations were predominantly of $\boldsymbol{a} / 2<111>$ type in the specimen after the creep deformation either with $176 \mathrm{MPa}$ or $250 \mathrm{MPa}$, and mixture of $\boldsymbol{a}<100>$ and $\boldsymbol{a} / 2<111>$ types in the specimens with only thermal aging.

Fig. 2 shows dislocation density as a function of the aging time at $1023 \mathrm{~K}$ for STDCW and SAACW. Dislocation densities after the creep test with $176 \mathrm{MPa}$ for $80 \mathrm{~h}$ at $1023 \mathrm{~K}$ are also shown. The figure shows that recovery of the dislocations induced by cold rolling was enhanced by the applied stress for SAACW. Also shown by comparison between STDCW and SAACW data is that the effects of SAA treatment on the recovery of the dislocations induced by cold rolling is small.

Precipitates were coarsened by the aging in SAA specimens. Because of high density of dislocations, precipitates did not grow in SAACW specimens by the aging. On the other hand, growth of precipitates was observed after the creep deformation of SAACW specimens. The precipitate size increased and the precipitate density decreased with the aging time for SAA specimens. Note that precipitate growth was not observed in SAACW specimens by the aging at $1023 \mathrm{~K}$ but observed after the creep tests. With the applied stress for creep deformation, however, the precipitate size is significantly smaller both for $176 \mathrm{MPa}$ and $250 \mathrm{MPa}$ than those in SAA specimens after aging. The results show that the some role to retard precipitate coarsening may remain in SAACW specimens after the recovery of the cold rolled dislocations. 